\title{
MRNA-derived Lung Cancer Vaccine BI 1361849
}

National Cancer Institute

\section{Source}

National Cancer Institute. mRNA-derived Lung Cancer Vaccine BI 1361849. NCI

Thesaurus. Code C111574.

A non-small cell lung cancer (NSCLC) vaccine containing six modified mRNAs, which encode six different NSCLC associated antigens, with potential antitumor and immunomodulatory activities. Upon intradermal administration, mRNA-derived lung cancer vaccine BI 1361849 may stimulate the immune system to mount both humoral and cellular responses against NSCLC cells. The six tumor-associated antigens (TAAs) encoded by these mRNAs are frequently expressed by NSCLC cells and are minimally expressed or absent in normal, healthy cells. 